\title{
BRUGADA SYNDROME- SKATING ON THIN ICE
}

\author{
Amit Kumar Jha ${ }^{1}$
}

${ }^{1}$ Senior Resident, Department of Cardiology, IPGME and R, Kolkata, West Bengal, India.

HOW TO CITE THIS ARTICLE: Jha AK. Brugada syndrome- skating on thin ice. J. Evolution Med. Dent. Sci. 2018;7(49):5328-5329, DOI: $10.14260 /$ jemds/2018/1178

\section{PRESENTATION OF CASE}

A 48 years old male patient presented with complaint of sudden-onset chest pain, which was retrosternal and localised. Pain was not associated with sweating or palpitation. Patient gave history of fever 2 days back. There was history of several episodes of palpitation and syncope prior to hospitalisation. No family history of diabetes, hypertension, syncope or sudden death in any of the close relatives was present.

On examination, patient was of average built, afebrile with regular pulse rate of $120 / \mathrm{min}$. Patient was in shock (70/60 mmHg). JVP was not raised with $\mathrm{SPO}_{2}$ of $96 \%$. Systemic examination was normal. With symptomatic treatment, patient's vital signs improved.

Fig. 1 (ECG 1) (Please refer ECG 1) Shows J point elevation with down sloping of ST-segment and T-wave inversion in leads $\mathrm{V} 1$ and $\mathrm{V} 2$ and sharp pointed $\mathrm{S}$ wave without slurring in lead V5.

Urgent Echocardiography was done for any Regional Wall Motion Abnormalities (RWMA) to rule out coronary artery disease. Echocardiogram was normal. Trop-T test by kit was negative.

Second ECG recorded after 6 hours is shown in Figure 2. Fig. 2 (ECG 2) (Please refer ECG 2) shows ST-segment elevation with saddleback configuration and merging of $\mathrm{T}$ wave with ST-segment.

Third ECG (Fig. 3) was recorded 12 hrs. after admission. Fig. 3 (ECG 3) (Please refer ECG 3) shows ST-segment elevation $<1 \mathrm{~mm}$ with positive $\mathrm{T}$ waves in a saddleback configuration in lead V2.

These three ECGs show presence of all three types of electrocardiographic patterns of Brugada syndrome. First one is typical Brugada type 1 with classical J point and STelevation. Second one shows saddleback configuration of type II and third one shows $<1 \mathrm{~mm}$ ST elevation in V2 with saddleback pattern suggestive of type III Brugada syndrome.

Sudden cardiac death is a public health concept incorporating features of natural, rapid and unexpected death. Brugada syndrome accounts for $4-12 \%$ of all sudden deaths and $\sim 20 \%$ of deaths in patients with structurally normal hearts.(1) It is an important cause of sudden unexpected death of men under age of 50 years in regions of world where this inherited syndrome is endemic.(1)

'Financial or Other Competing Interest': None.

Submission 09-09-2018, Peer Review 15-11-2018,

Acceptance 21-11-2018, Published 03-12-2018.

Corresponding Author:

Dr. Amit Kumar Jha,

C/o. Raj Mohan Jha,

$3^{\text {rd }}$ Street, Chunapur Road,

Sipahi Tola,

Purnia-854301

Bihar, India.

E-mail: amitdmch99@gmail.com

DOI: $10.14260 /$ jemds $/ 2018 / 1178$

\section{(c) $(1)(5)$}

Brugada syndrome is characterized by an ST-segment elevation in the right precordial ECG leads and is responsible for high incidence of sudden death in individuals with structurally normal hearts.(2) Prevalence has been estimated to be $5 / 10,000$. As many patients present with concealed forms of disease, hence real prevalence may be still higher. (3) Brugada syndrome occurs due to mutation in cardiac sodium and calcium channel and is more frequently seen in males than females.(3)

\section{CLINICAL DIAGNOSIS}

Brugada Syndrome.

DIFFERENTIAL DIAGNOSIS
- RBBB
- Early Repolarisation Syndrome
- Myocardial Ischaemia/ Infarction
- Pericarditis
- Duchenne Muscular Dystrophy
- Hyperkalaemia
- Hypercalcaemia
- Hypothermia,
- ARVC

\section{PATHOLOGICAL DISCUSSION}

Investigations carried out at the time of admission showed Haemoglobin- 13.0 gm\%, Total leucocytes count6100/cu.mm, Differential leucocytes count- N59, L33, E2, M6, Platelet count- 1.5 lacks/cu.mm, Blood sugar (Random)- 125 $\mathrm{mg} \%$, Blood urea- $49 \mathrm{mg} \%$ and Serum creatinine- $2.0 \mathrm{mg} \%$. Serum electrolytes were within normal limits. First ECG recorded at the time of admission is shown in Figure 1.

Brugada syndrome is a channelopathy, in which dysfunction of cardiac channels taking part in the formation of action potential occurs. The electrical disorder is primary, i.e. without any underlying structural heart disease.(3) It is inherited as an autosomal dominant trait and can be sporadic in upto $60 \%$. Mutations leading to a loss of function of the sodium channel (Either through SCN5A or GPD-1L) and loss of function of the cardiac calcium channel CACNA1c (Cav1.2) and its $\beta$-subunit CACNB2b are responsible for Brugada syndrome.(4)

Three types of ECG patterns are described (a) Type-1= Coved ST-segment elevation $\geq 2 \mathrm{~mm}$ with descending slope and T-wave inversion in more than 1 right precordial leads; (b) Type-2= ST-segment elevation followed by a positive or biphasic T-wave with a saddleback configuration; (c) Type-3= right precordial ST-segment elevation $\leq 1 \mathrm{~mm}$ with either a coved-type or a saddleback morphology.(3) Although, all three patterns can be present in Brugada patients, only type-1 ECG pattern is diagnostic of the syndrome.(5)

ECG typically fluctuates over time in Brugada patients, and thus can change from type- 1 to type- 2 or type- 3 , or even be transiently normal. In present case, all three types of ECG patterns were seen in same patient. Patients with type-1 ECG 
without clinical criteria are known as idiopathic Brugada ECG pattern and not Brugada syndrome.(5)

Most dreaded complication of Brugada syndrome is sudden cardiac death, usually due to ventricular arrhythmia occurring at rest, especially during sleep due to increased vagal tone. Abnormal phase 1 of ventricular depolarisation is basic abnormality in Brugada syndrome. This Phase 1 of ventricular action potential is determined by the balance between inward sodium and calcium currents (INa and ICa), and transient outward potassium currents (Ito). When positive inward currents are impaired with respect to positive outward currents, characteristic ST-segment elevation on ECG are seen.(3) Interventions that decrease inward positive currents (Sodium or calcium blockers, vagal stimulation, fever etc.) increase ST-segment elevation. Interventions that increase inward positive currents (Sodium or calcium opener, b-adrenergic stimulation etc.) decrease ST-segment elevation. Presence of greater density of Ito currents in right ventricle and in male makes Brugada syndrome a disease mainly of the right ventricle and predominantly of males. (3)

Diagnosis of Brugada syndrome is done by appearance of Type 1 ECG features, either spontaneously or after induction by $\mathrm{Na}$ channel blocker and by presence of one of the following- Self terminating polymorphic VT, documented VF, inducible ventricular arrhythmias, family history of SCD $<45$ years, presence of coved-type ECG in family members, syncope and nocturnal agonal respiration.(6) Asymptomatic patients with a normal ECG at baseline and no inducible VF during EPS represent the lowest risk population, whereas patients with syncope, spontaneous type-1 ECG and VF inducibility during EPS have worst outcome.(3)

Shows J point elevation with down sloping of ST-segment and T-wave inversion in leads V1 and V2 and sharp pointed S-wave without slurring in lead V5.

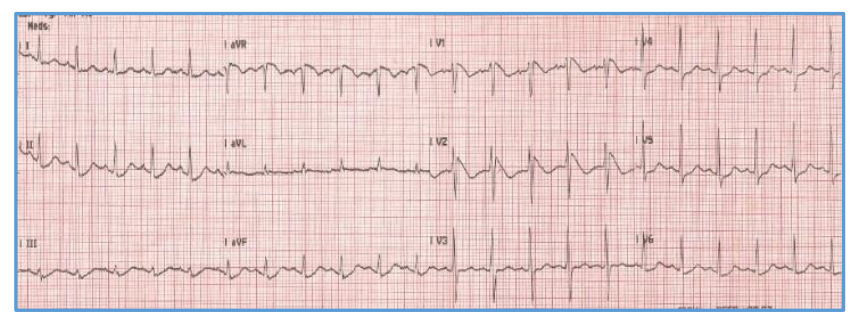

Figure 1. (ECG 1)

Shows ST-segment elevation with saddleback configuration and merging of T-wave with ST-segment.

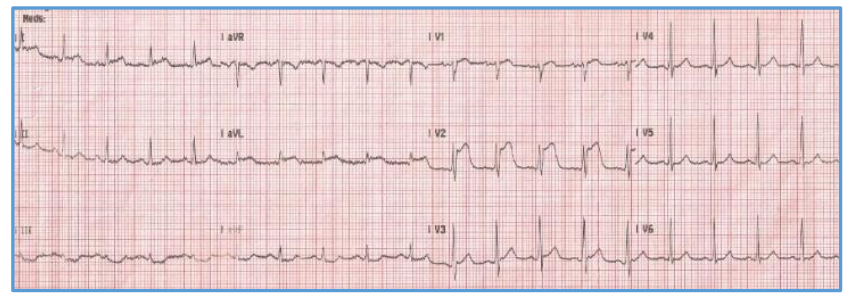

Figure 2. (ECG 2)
Shows ST-segment elevation $<1 \mathrm{~mm}$ with positive $\mathrm{T}$-waves in a saddleback configuration in lead V2.

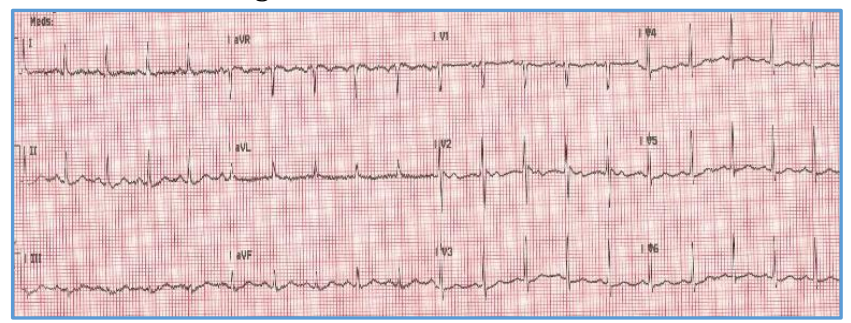

Figure 3. (ECG 3)

\section{DISCUSSION OF MANAGEMENT}

Quinidine, an Ito inhibitor, is the only drug, which is effective in BS. Unfortunately, this old drug is now difficult to get. ICD implantations in BS patients who have survived cardiac arrest or have a history of syncope and documented ventricular arrhythmia.

\section{FINAL DIAGNOSIS}

Brugada Syndrome.

\section{REFERENCES}

[1] Antzelevitch C, Brugada P, Brugada J, et al. Brugada syndrome: a decade of progress. Circ Res 2002;91(12):1114-8.

[2] Brugada P, Brugada J. Right bundle branch block, persistent ST segment elevation and sudden cardiac death: a distinct clinical and electrocardiographic syndrome. A multicenter report. J Am Coll Cardiol 1992;20(6):1391-6.

[3] Brugada P, Benito B, Brugada R, et al. Brugada syndrome: update 2009. Hellenic J Cardiol 2009;50(5):352-72.

[4] Antzelevitch C, Pollevick GD, Cordeiro JM, et al. Lossof-function mutations in the cardiac calcium channel underlie a new clinical entity characterized by STsegment elevation, short QT intervals and sudden cardiac death. Circulation 2007;115(4):442-9.

[5] Wilde AAM, Antzelevitch C, Borggrefe M, et al. Proposed diagnostic criteria for the Brugada syndrome. Eur Heart J 2002;23(21):1648-54.

[6] Antzelevitch C, Brugada P, Borggrefe M, et al. Brugada syndrome: report of the second consensus conference: endorsed by the Heart Rhythm Society and the European Heart Rhythm Association. Circulation 2005;111(5):659-70. 